\title{
S-21-2 Pyridoxine Responsive and Unresponsive Homocystinuria
}

\author{
J.P.KRAUS, and V.KoẑICH
}

Department of Pediatrics, University of Colorado School of Medicine, Denver, CO 80262 (USA)

\section{INTRODUCTION}

Cystathionine $\beta$-Synthase (CBS) deficiency is an autosomal recessively inherited disorder of sulfur amino acid metabolism and the major cause of homocystinuria in man. Its clinical variations and biochemical heterogeneity are well documented [1]. Nearly all patients have dislocated optic lenses and some exhibit other clinical manifestations including mental retardation and thrombotic vascular disease. CBS catalyzes the condensation of homocysteine and serine to form cystathionine and ultimately cysteine in the transsulfuration pathway. This pathway removes the sulfur moiety irreversibly from the methionine conservation cycle. CBS requires pyridoxal 5'-phosphate (PLP) as coenzyme. Some affected individuals, but not all, respond to treatment with pyridoxine $\left(B_{6}\right)$, the vitamin precursor of PLP, with a marked fall in their characteristically elevated plasma and urinary concentrations of methionine and homocyst(e)ine. In previous biochemical studies [2] we attempted to correlate in vivo responsiveness to pyridoxine with in vitro stimulation of CBS activity by PLP. At the present time, studies are being carried out to correlate the mutations in the CBS gene to the structure of the enzyme and its responsiveness to PLP.

\section{BIOCHEMICAL STUDIES}

In order to determine the affinity of normal and mutant CBS apoenzymes for PLP we have developed conditions for growth of human skin fibroblasts in a medium depleted of $B_{6}$ vitamers. Cellular PLP content fell rapidly when cells were grown in medium containing no pyridoxal (PL) and hydroxylamine-treated human serum. After four passages, the PLP content was lowered to $6 \%$ (from 24 to $1 \mathrm{ng}$ PLP/mg cell protein). Depletion of cellular PLP was associated with a sharp fall in the ratio of CBS holoenzyme/total enzyme from 0.7 to $<0.1$, indicating that, in the PLP depleted cells, CBS was present predominantly in the apoenzyme form. Cells from 3 controls, 4 in vivo responsive, and 2 in vivo nonresponsive patients where grown under these conditions.

1. In vitro Estimation of PLP Kinetics. Determinations of $\mathrm{K}_{m}$ values of aposynthase for PLP in extracts of PLP-depleted cells from three controls and the six mutant lines were estimated from Hill plots. The apparent $\mathrm{K}_{\mathrm{m}}$, of apo-CBS for PLP in the three control lines ranged from 52 to $85 \mu \mathrm{M}$ (mean $63 \mu \mathrm{M}$ ). The four lines from in vivo responsive patients had approximately two to four times higher values of $145-200 \mu \mathrm{M}$, whereas the two lines from in vivo non-responsive patients showed much more elevated $\mathrm{K}_{\mathrm{m}}$ values of $990 \mu \mathrm{M}$ and $4,000 \mu \mathrm{M}, \sim 16-$ and 63 -fold that of the controls [2].

2. Effect of PLP Repletion on CBS Activity. To determine whether these apparent $\mathrm{K}_{m}$ differences reflected the situation in intact cells, PLP-depleted cells were propagated in media containing increasing concentrations of pyridoxal. Maximal saturation of apoCBS with PLP in control fibroblasts was observed at a medium pyridoxal concentration of 10 $\mathrm{ng} / \mathrm{ml}$ or less, whereas $25-50 \mathrm{ng} / \mathrm{ml}$ was required in fibroblasts from CBS-deficient patients responsive to pyridoxine in vivo, and at $100 \mathrm{ng} / \mathrm{ml}$, CBS holoenzyme formation was still increasing in cells from in vivo nonresponsive patients. 
3. Significance. When the in vitro kinetic and PLP-repletion data are interpreted together, we believe both the affinity of CBS for PLP and the cell's ability to accumulate PLP assume importance in understanding in vivo responsiveness to oral pyridoxine in CBS-deficient patients. We proposed [2] that those patients whose cells contain a mutant CBS with a moderately reduced affinity for PLP (2-5 times less than control) are able to increase cellular PLP content sufficiently after pyridoxine supplementation so that holosynthase activity rises above that critical value to prevent accumulation of homocyst(e)ine and methionine. Pyridoxine nonresponsiveness, on the other hand, is observed because the cell contains a mutant enzyme whose affinity for PLP is so reduced (20-70 times less than control) that, despite any feasible pyridoxine supplements, the cell is unable to increase PLP content enough to stimulate any appreciable formation of synthase holoenzyme.

\section{MOLECULAR ANALYSIS OF CBS MUTATIONS}

1. Screening for CBS Mutations by Expression in E. coli. We have cloned the human CBS cDNA and inserted its coding sequence into a bacterial expression vector. This "wild type" construct yields significant expression of CBS activity in E. coli. Pathogenic mutation leads to loss of enzymatic activity, thus, functional expression of CBS activity from each allele can be tested separately. We are now replacing the segments of the normal human sequence (segments: NP 1-608bp, XB 411-941bp, BK 941-1669bp) with PCR-amplified segments derived from the homozygous and heterozygous patients to localize the sites of CBS mutations. E.coli cells are then transformed with these vectors (in which one of the CBS segments originates from the patient CDNA) and subsequently the CBS activity is measured in $E$. coli cell extracts.

2. Characterization of CBS Subunits in Patient 366. Patient 366 is a mildly affected, pyridoxine-responsive, male homocystinuric patient with no detectable catalytic activity in extracts of cultured fibroblasts, and a small amount $(\sim 13 \%)$ of cross-reacting material [3]. When mRNA was prepared from his fibroblasts and translated in vitro, however, the molecular defect of his CBS deficiency was clearly revealed. AntiCBS antiserum precipitated two polypeptides differing by $\sim 7 \mathrm{kDa}$. In addition to the subunit of normal size $(63 \mathrm{kDa})$, an abnormally small $(56 \mathrm{kDa})$ polypeptide was also found in cell-free translations prepared from the patient's fibroblasts and those from his father (cell line 368), whereas only CBS subunits of normal size were observed when mRNA from the mother's fibroblast was used (cell line 367) [4].

TABLE 1: SCREENING FOR MUTATIONS IN PATIENT 366 BY EXPRESSION IN E. coli.

\begin{tabular}{|c|c|c|c||}
\hline $\begin{array}{c}\text { SEGMENT } \\
\text { INSERTED }\end{array}$ & $\begin{array}{c}\text { FRACTION OF } \\
\text { COLONIES WITH } \\
\text { CBS ACTIVITY }\end{array}$ & $\begin{array}{c}\text { MIXED CULTURE } \\
\% \text { CONTROL } \\
\text { ACTIVITY }\end{array}$ & $\begin{array}{c}\text { DEDUCED } \\
\text { SEGMENT } \\
\text { ZYGOSITY }\end{array}$ \\
\hline NP & $7 / 8$ & 98 & $\mathrm{AA}$ \\
\hline $\mathrm{XB}$ & $3 / 7$ & 40 & $\mathrm{Aa}_{2}$ \\
\hline $\mathrm{BK}$ & $4 / 18$ & 22 & $\mathrm{Aa}_{1}$ \\
\hline
\end{tabular}

3. Screening for Mutations in Patient 366 by Expression. The result of the CBS assays in $E$. coli extracts (Table 1) show that four out of seven colonies containing segment $X B$ 
and 14 out of 18 colonies having segment BK had no activity. The activities of the colony mixes were consistent with these data. Therefore, we concluded that one of the mutations must be in the segment XB and the other one in segment BK while the amino-terminal segment NP appeared to be normal. Because the segments NP and XB overlap by $\sim 200 \mathrm{bp}$, these results suggested that one mutation lies between the nucleotides 608-941 and the second one between nucleotide 941 and the end of the coding sequence (nucleotide 1656).
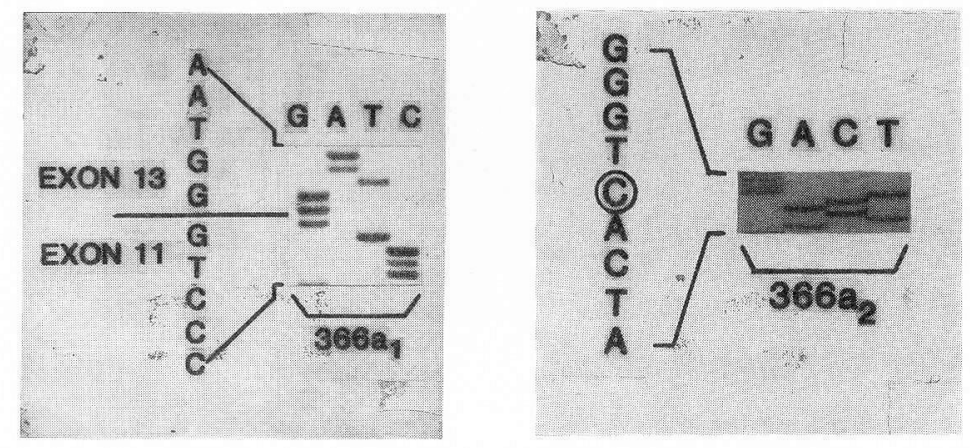

Fig. 1 DNA sequences of PCR-amplified cDNA from patient 366. Sense strands are shown. Left: Sequence derived from the junction of exon 11 and exon 13 showing the absence of exon 12. Right: Sequence of nucleotides 829 to 837. (C) indicates the abnormal $\mathrm{C}$ at position 833 in place of a normal T.

4. DNA Sequencing of the Mutated Segments. Fig. 1 shows a partial sequences of the BK segment (left) and the XB segment (right) from patient 366. It is obvious from the sequences that the patient is missing the entire exon 12 in his BK segment, and that there is a $T \rightarrow C$ change at position 833 within the $X B$ segment. This changes the isoleucine codon AIT 278 to ACET coding for threonine. We suspected that the absence of exon 12 is a result of missplicing of CBS pre-mRNA due to a mutation at or near one of the splice junctions. Genomic DNA from the father (\#368), who also had both the shorter polypeptide and the missing exon, was sequenced. Fig. 2 (top) shows that this is indeed the case. The acceptor splice junction of intron 11 is changed in the $a_{1}$ allele from the consensus dinucleotide $\underline{A} G$ to $\underline{\mathrm{CG}}$. Consequently, the next acceptor splice site of intron 12 is used to join exon 11 to exon 13. DNA sequence of segment $X B$ from the mother (\#367) (Fig.2, bottom) confirms the finding in her son that allele $a_{2}$ contains the I278T change.

5. Conclusion. Patient 366 has inherited from his father the point mutation $A \rightarrow C$ in the acceptor splice junction of intron 11. This leads to an elimination of 45 amino acid residues (exon 12, trp 408 to gly 453) and the appearance of a shorter subunit in an in vitro translation of his mRNA. The mutation inherited from his mother is a point mutation in the isoleucine codon 278 (ATT $\rightarrow$ ACT) causing a threonine substitution at this site. It is likely that it is this allele which is responsible for the pyridoxine responsiveness of CBS in 

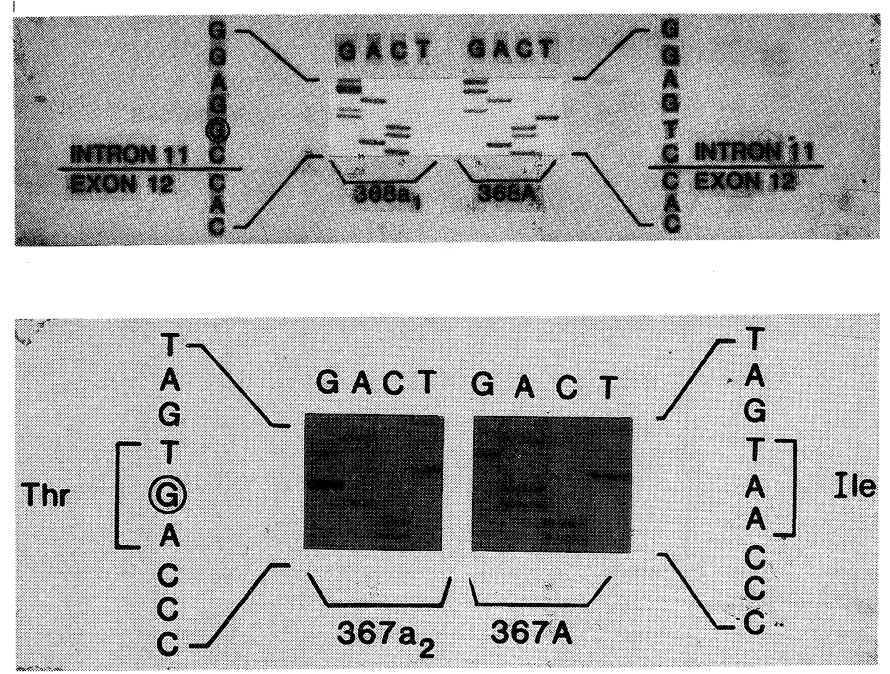

Fig. 2 DNA sequences of PCR-amplified DNA from parents of 366. Antisense strands are shown. Top: Sequence derived from father's genomic DNA from the junction of intron 11 and exon 12. The mutant allele $368 a_{1}$ contains a (G) instead of $T$ found on the normal allele 368A. Bottom: Sequence from mother's cDNA confirming the lle $287 \rightarrow$ Thr change detected in her son. $367 a_{2}$, mutant allele; 367A, normal allele.

this patient. Definitive answer will have to await the elucidation of the tertiary and quaternary structure of the enzyme and the delineation of the residues forming the coenzyme binding pocket.

IV. REFERENCES

[1] Mudd, S.H., Levy, H.L., and Skovby, F. (1989): Disorders of Transsulfuration in The Metabolic Basis of Inherited Disease, ed. by Scriver, C.R., Beaudet, A.L., Sly, W.S., and Valle, D., McGraw Hill, New York, pp. 693-734.

[2] Lipson, M.H., Kraus, J., and Rosenberg, L.E. (1980): Affinity of cystathionine $\beta$ synthase for pyridoxal 5'-phosphate in cultured cells. J. Clin. Invest. 66, 188-193.

[3] Skovby, F., Kraus, J., Redlich, C., and Rosenberg, L.E. (1982): Immunochemical studies on cultured fibroblasts from patients with homocystinuria due to cystathionine $\beta$-synthase deficiency. Am. J. Genet. 34, 73-83.

[4] Skovby, F., Kraus, J.P., and Rosenberg, L.E. (1984): Homocystinuria: Biogenesis of cystathionine $\beta$-synthase subunits in cultured fibroblasts and in an in vitro translation system programmed with fibroblast messenger RNA. Am. J. Human Genet. 36, 452-459. 